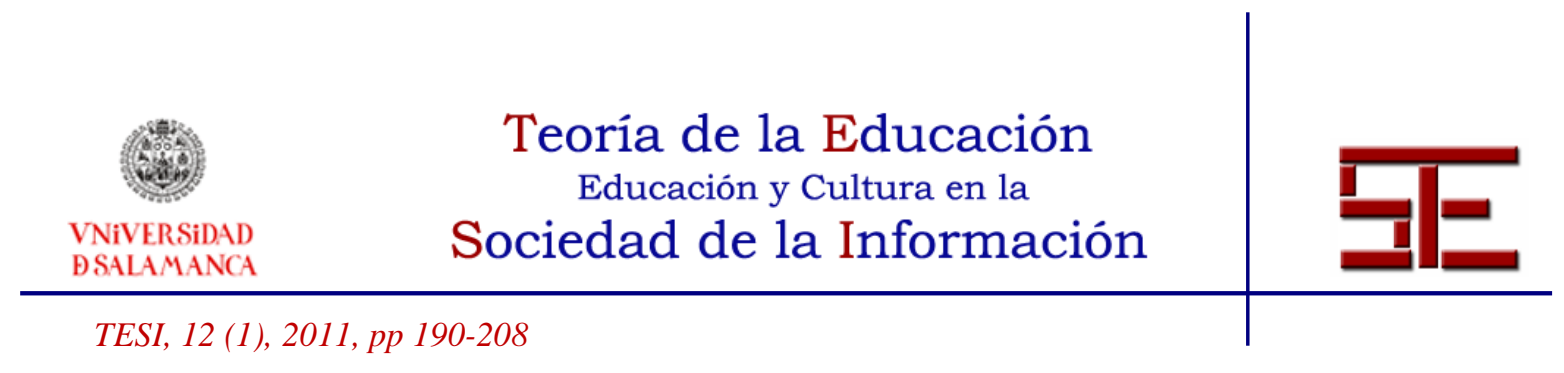

\title{
WEBQUEST Y WIKIS: BÚSQUEDA DE INFORMACIÓN EN RED Y DESARROLLO DE COMPETENCIAS EN COLABORACIÓN
}

Resumen: En la formación universitaria se está apostando por estrategias y recursos didácticos, -que aprovechan las potencialidades de diferentes instrumentos digitales-, como las Webquests en tanto metodologías de investigación colaborativa apoyada en la búsqueda de información y en la utilización de contenidos alojados en Internet para la realización de proyectos. Los cuales pueden articularse a partir de herramientas 2.0 como las wikis, por su gran versatilidad y capacidad para generar conocimiento de forma colaborativa mediante la creación de contenidos on-line.

En la asignatura virtual de Educación en el ámbito rural $^{21}$ se ha diseñado una actividad formativa en colaboración basada en la filosofía de las webquests y apoyada en el uso de las wikis, - configurando lo que se denominó Gameproject- Del Moral; Villalustre (2007b), que promueve el acceso y gestión de la información para elaborar un proyecto de intervención socio-educativo.

Tras su implementación en varios años, se preguntó a 161 estudiantes sobre las competencias que consideraban haber desarrollado y/o consolidado con el trabajo colaborativo planteado. Éstos destacaron mayoritariamente las habilidades para la investigación, la recogida y tratamiento de la información, y otras más específicas vinculadas al futuro desempeño de su actividad profesional. Hay que destacar que los estudiantes sin experiencia previa en cursos de formación virtual consideraron haber consolidado más las competencias vinculadas al uso de herramientas informáticas.

Palabras clave: Webquest; wikis; competencias; información digital; Internet.

\footnotetext{
${ }^{1}$ Optativa perteneciente a la titulación de Pedagogía de la Universidad de Oviedo y ofertada al Campus Virtual Compartido del G9, el cual está formado por nueve Universidades: Cantabria, País Vasco, publica de Navarra, Oviedo, Zaragoza, Islas Baleares, La Rioja, Extremadura y Castilla-La Mancha.
}

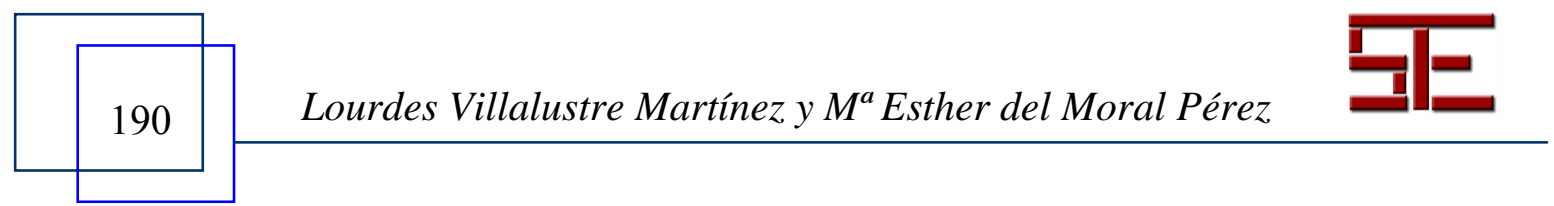




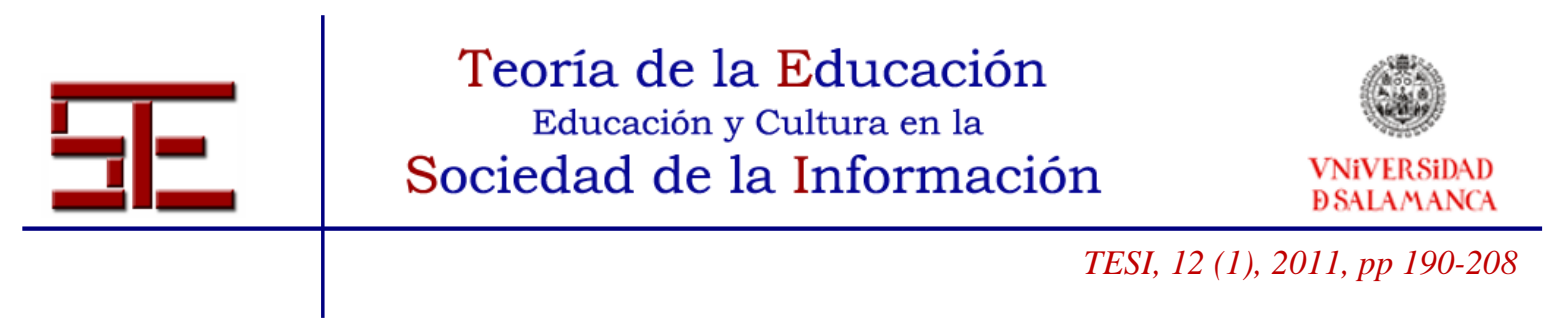

\title{
WEBQUEST AND WIKI: SEARCH OF INFORMATION IN INTERNET AND DEVELOPMENT OF COMPETENCES IN COLLABORATIVE
}

\begin{abstract}
In university education is committed to strategies and resources, -that exploit the potential of digital tools-, such as Webquests as supported collaborative research methodologies in the search for information and the use of content on the Internet for conducting projects. Which can be articulated from 2.0 tools like wikis, for its versatility and capacity to generate knowledge collaboratively by creating online content.
\end{abstract}

In the virtual subject of Education in the rural area was designed a collaborative learning activity based on the philosophy of webquests and supported by the use of wikis, - setting up what was called Gameproject - that facilitates access and management information to create a project of socio-educational intervention.

After its implementation in several years, 161 students were asked about competences they considered to have developed and consolidated with the proposed collaborative work. The students stressed the skills to research, collection and processing of information, and other more specific competences relating to the future performance of their work. Noted that students without prior experience in virtual training, considered to have consolidated over the powers associated with the use of tools.

Keywords: Webquest; wikis; competences; digital information; Internet.

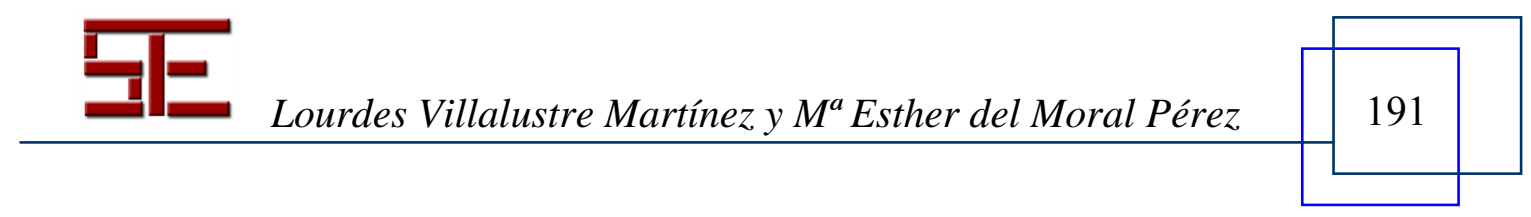




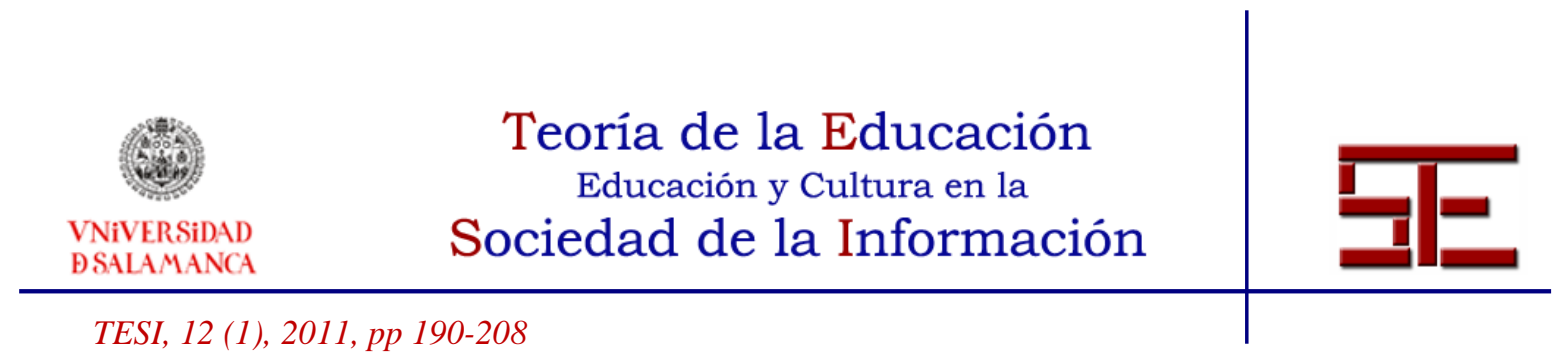

\title{
WEBQUEST Y WIKIS: BÚSQUEDA DE INFORMACIÓN EN RED Y DESARROLLO DE COMPETENCIAS EN COLABORACIÓN
}

Fecha de recepción: 08/11/2010; fecha de aceptación: 17/02/2011; fecha de publicación: 31/03/2011

\author{
Lourdes Villalustre Martínez \\ villalustrelourdes@uniovi.es \\ Universdiad de Oviedo \\ $\mathrm{M}^{\mathrm{a}}$ Esther del Moral Pérez \\ emoral@uniovi.es \\ Universidad de Oviedo
}

\section{1.- INTRODUCCIÓN}

Las Webquests constituyen una estrategia didáctico-metodológica novedosa al servicio del aprendizaje basada en la resolución de problemas y en la investigación de manera colaborativa, que aprovecha las posibilidades que brindan las Tecnologías de la Información y la Comunicación (TIC). Esta metodología de trabajo, apoyada en el uso de Internet como recurso para la búsqueda y gestión de información, tiene como objetivo facilitar la adquisición del conocimiento de manera significativa, estimulando en los estudiantes universitarios la indagación, la creatividad, la toma de decisiones, etc. Así como el desarrollo de competencias de diversa índole (Del Moral; Villalustre, 2005).

Una Webquest puede definirse como la formulación de una actividad de investigación orientada a la resolución de un problema o a la realización de un proyecto mediante una metodología colaborativa a partir de pequeños grupos de trabajo, y empleando como principales recursos aquellos que ofrece la red Internet (Del Moral; Villalustre, 2007a). Según lo concibió Bernie Dodge (1995) en las Webquests la información con la que interactúan los estudiantes proviene total o parcialmente de recursos procedentes de Internet. En este sentido, se convierten en interesesantes estrategias didácticas para favorecer el acceso, selección y utilización de información digital para la realización de proyectos en colaboración.

No cabe duda, que aplicar una metodología que apuesta por la realización de proyectos colaborativos favorece el desarrollo cognitivo de toda la comunidad de aprendizaje,

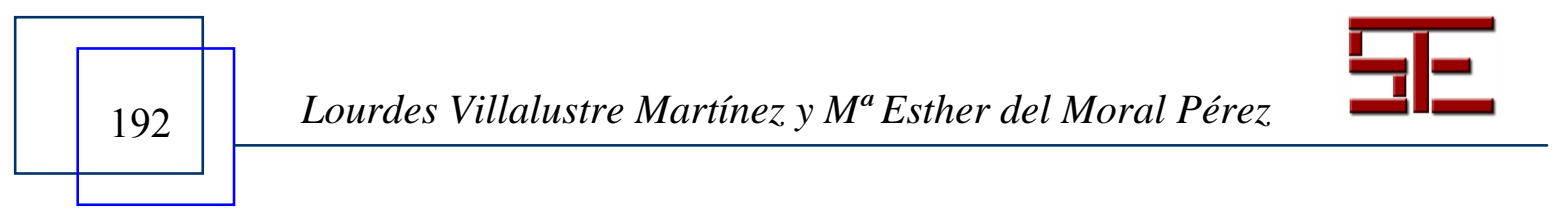




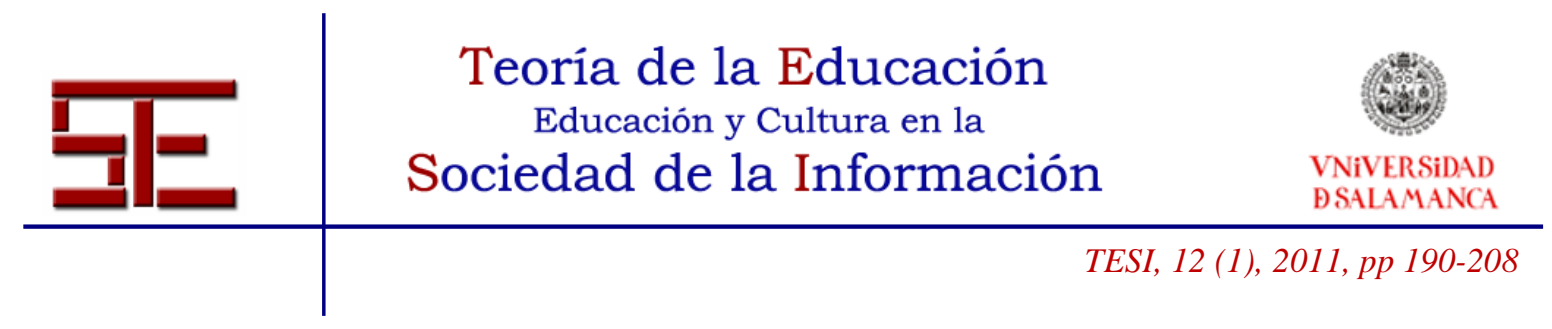

puesto que las diferentes aportaciones e ideas individuales que cada miembro de la misma aporta, con el apoyo de las diversas herramientas de comunicación on line, y de las interacciones que se producen entre docentes y estudiantes en los contextos virtuales, se ven enriquecidas al orientarse a la consecución de un objetivo común (Del Moral; Villalustre, 2006). Al mismo tiempo, posibilita una enseñanza más flexible y abierta que potencia el trabajo autónomo de los estudiantes al proporcionarles un mayor control sobre su propio proceso de aprendizaje.

Desde esta perspectiva, el aprendizaje colaborativo propiciado por las Webquests supone que los estudiantes deben trabajar de forma conjunta para culminar una tarea $\mathrm{o}$ proyecto. Barkley, Cross y Major (2007: 17) identifican el trabajo colaborativo con "las actividades de aprendizaje expresamente diseñadas para parejas o pequeños grupos interactivos y realizadas por ellos". De esta definición se desprenden tres características básicas del aprendizaje colaborativo: 1) ha de ser intencional, es decir, debe existir una estructuración previa de las actividades que respondan a una finalidad concreta; 2) dichas actividades deben desarrollarse colaborativamente, por tanto, todos los estudiantes de un mismo grupo deben comprometerse activamente a desarrollar el trabajo planteado; 3) debe dar lugar a un aprendizaje significativo, con el que los discentes adquieran nuevos conocimientos en colaboración y de manera activa, los cuales pasarían a formar parte de su estructura cognitiva.

La colaboración en el desarrollo de un proyecto, planteado a través de una Webquest, requiere de la toma de decisiones conjunta y constante por parte de los implicados, mediante fórmulas que fomenten el consenso para elaborar socialmente el conocimiento de forma compartida. Desde esta visión social del aprendizaje el proceso de adquisición de conocimiento se genera a partir de la construcción conjunta del mismo. En este sentido, Scardamalia, Bereiter y Lamon (1994), Lave (1997), Jonassen (1999), Wenger (2001), etc., consideran que el modo más natural de aprendizaje es aquel que se produce mediante la colaboración e intercambio entre un grupo de sujetos para alcanzar un objetivo común. Concepción propugnada por Vygotsky (1995) quien sostiene que aprender es, por naturaleza, un fenómeno social, y que la adquisición de nuevos conocimientos es resultado de la interacción entre varios sujetos que participan en un proyecto conjunto.

En la medida que los contextos virtuales contemplen espacios sociales, y se propicie en ellos la creación de comunidades de aprendizaje a partir del uso de diferentes herramientas digitales, se contribuirá a la contextualización del aprendizaje y a dotarle a

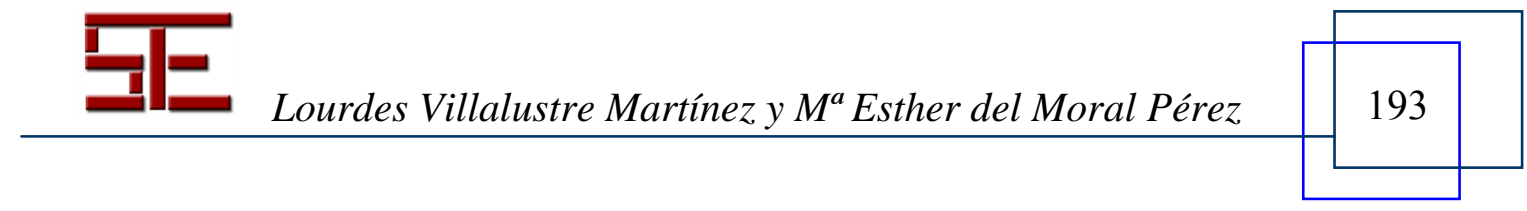




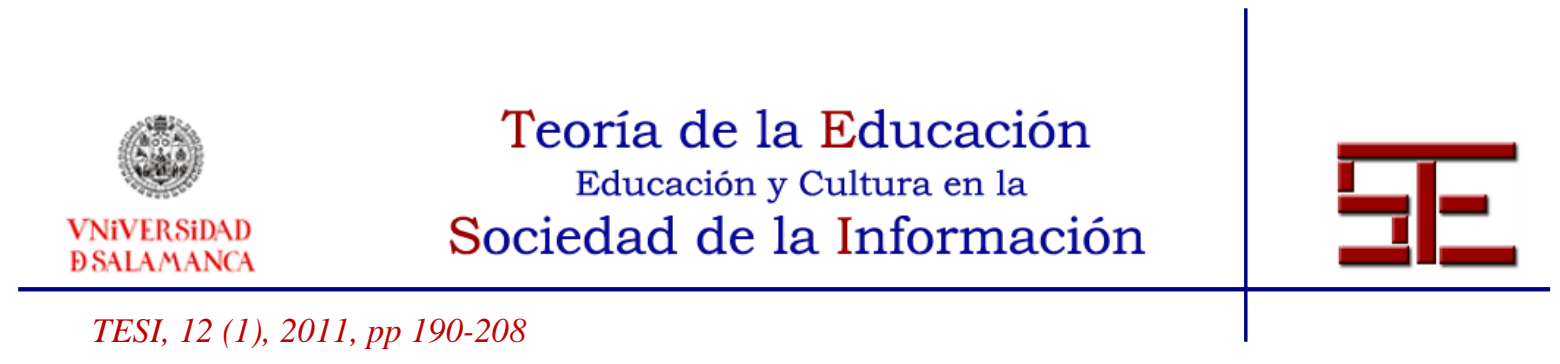

éste de significado. Con este objetivo han ido surgiendo diversas herramientas tecnológicas que, cada vez más, se integran en los entornos virtuales, y que conforman el denominado software social (Owen, Grant, Sayers, Facer, 2006), entre las que destacamos las wikis ya que amplían las posibilidades de comunicación, interacción e intercambio de información.

De este modo, debido a su naturaleza abierta y flexible, las wikis se convierten en unas aplicaciones potenciadoras del aprendizaje colaborativo, al posibilitar a los estudiantes relacionarse, compartir y contrastar diversidad de ideas, experiencias $\mathrm{y} / \mathrm{u}$ opiniones en relación a un mismo tema, solicitar apoyo, comparar y consensuar soluciones para un problema dado, redactar informes conjuntos, desarrollar un proyecto, etc... Todo ello hace que su utilización sea considerada una estrategia muy motivadora al lograr materializar las tareas y plasmar las ejecuciones tanto individuales como grupales en aplicaciones reales que permiten la visibilidad de todo el proceso creativo-formativo (Del Moral y Villalustre, 2008a). La filosofía que subyace en las wikis participa de los postulados socio-constructivistas del aprendizaje, al favorecer el desarrollo de proyectos colaborativos, lo cual hace que éstas sean contempladas como valiosas aliadas tecnológicas para canalizar y gestionar la información digital y el trabajo grupal de los estudiantes.

Así pues, en el ámbito universitario son numerosas las ventajas que presenta la integración de las wikis para hacer viable la realización de los proyectos colaborativos en red, ya que son herramientas capaces de suscitar la participación en la construcción compartida del conocimiento. La formulación de actividades formativas a través de webquests articuladas mediante wikis puede contribuir a hacer efectiva la consecución de los objetivos de aprendizaje y el proceso de adquisición de competencias específicas, -es decir, las propias de cada perfil profesional de cada grado-, y transversales o genéricas, categorizadas en instrumentales, interpersonales y sistémicas, tal como se definían en el Proyecto Tuning Educational Structures in Europe (2003: 81-84):

1. Competencias instrumentales; referidas a las habilidades cognoscitivas y a las capacidades metodológicas de adaptación al medio, así como a las destrezas tecnológicas y lingüísticas: comunicación oral y escrita en el propio idioma y dominio de destrezas lingüísticas de una segunda lengua; junto a las habilidades básicas para el manejo de TIC (Tecnologías de la Información y Comunicación); resolución de problemas; etc.

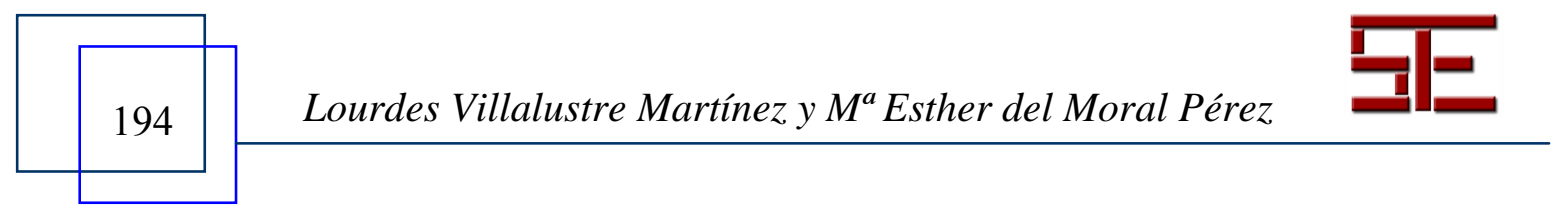




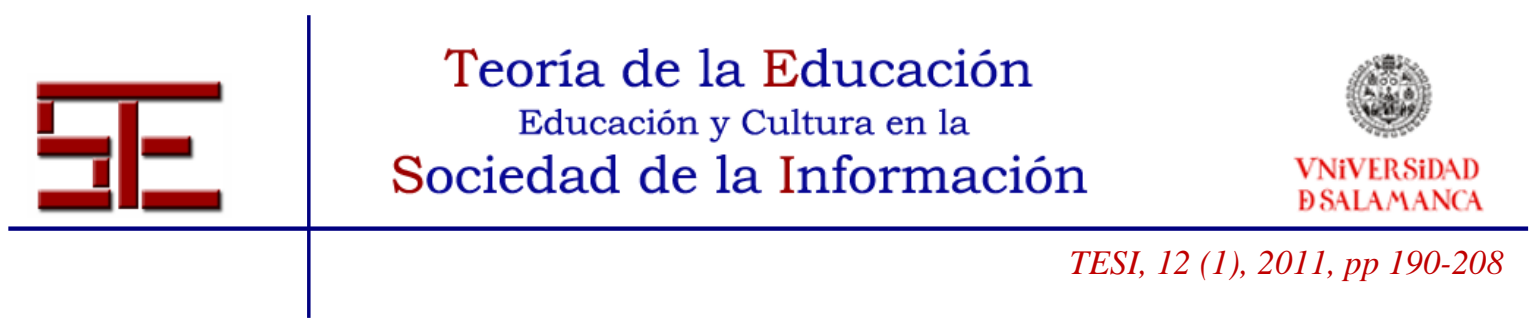

2. Competencias interpersonales; entre las que cabe mencionar las habilidades necesarias para desarrollar un proceso de crítica y autocrítica, así como las destrezas sociales utilizadas en la ejecución de un trabajo colaborativo.

3. Competencias sistémicas; relacionadas con la capacidad de comprensión, sensibilidad y conocimiento que permitan dar una visión de conjunto de la realidad global. Y otras como la capacidad de aplicar conocimientos teóricos en la práctica; desarrollo de habilidades de investigación; capacidad de generar ideas innovadoras y fomento de la creatividad; etc.

La adopción de una metodología didáctica flexible basada en la realización de proyectos colaborativos a través de webquest, y apoyada en el uso de los recursos que ofrece la red Internet y diferentes herramientas digitales, tales como las wikis, posibilita a los estudiantes adquirir nuevos aprendizajes de manera significativa y colaborativa, propiciando el desarrollo de las competencias y habilidades más específicas vinculadas al futuro desempeño de su actividad profesional.

\section{2.- WEBQUEST Y WIKIS EN RURALNET PARA FACILITAR EL ACCESO Y TRATAMIENTO DE INFORMACIÓN DIGITAL}

En la asignatura Educación en el ámbito rural (Ruralnet), -optativa perteneciente a la titulación de Pedagogía de la Universidad de Oviedo y ofertada al Campus Virtual Compartido del $\mathrm{G}^{22}{ }^{2}$, se diseñó una actividad formativa para potenciar el aprendizaje colaborativo y constructivista basada en la filosofía de las Webquests (Dodge, 1997), pero añadiendo otra serie de componentes motivacionales -descritos más adelante-, configurando lo que se denominó Gameproject (Del Moral y Villalustre, 2007b). En él se presentan, de manera detallada, la tarea que han de desarrollar los estudiantes y los pasos que pueden seguir para llevarla a cabo, los criterios de evaluación que se van a aplicar, etc... asegurando que todos los miembros del grupo conozcan la finalidad del proyecto, así como el procedimiento para su elaboración.

La presentación de la actividad colaborativa se apoyó en el famoso juego de simulación social de Los Sims, de este modo tan atractivo y motivador se solicitaba a los

${ }^{2}$ El Campus Virtual Compartido del G9 esta formado por nueve Universidades: Cantabria, País vasco, PÚblica de Navarra, Oviedo, Zaragoza, Islas Baleares, La Rioja, Extremadira y Castilla-La Mancha

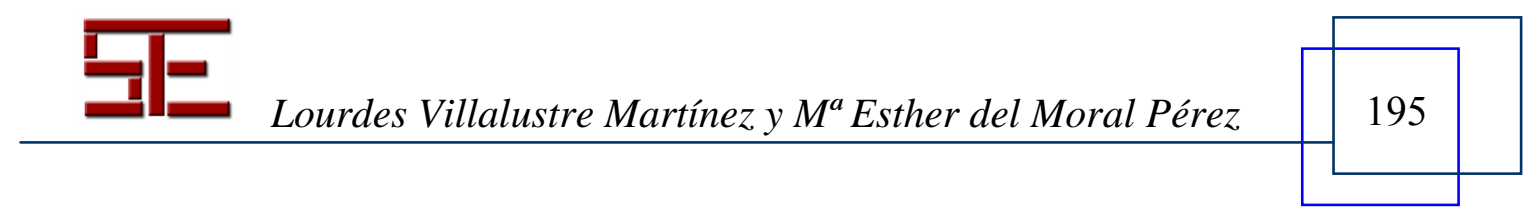




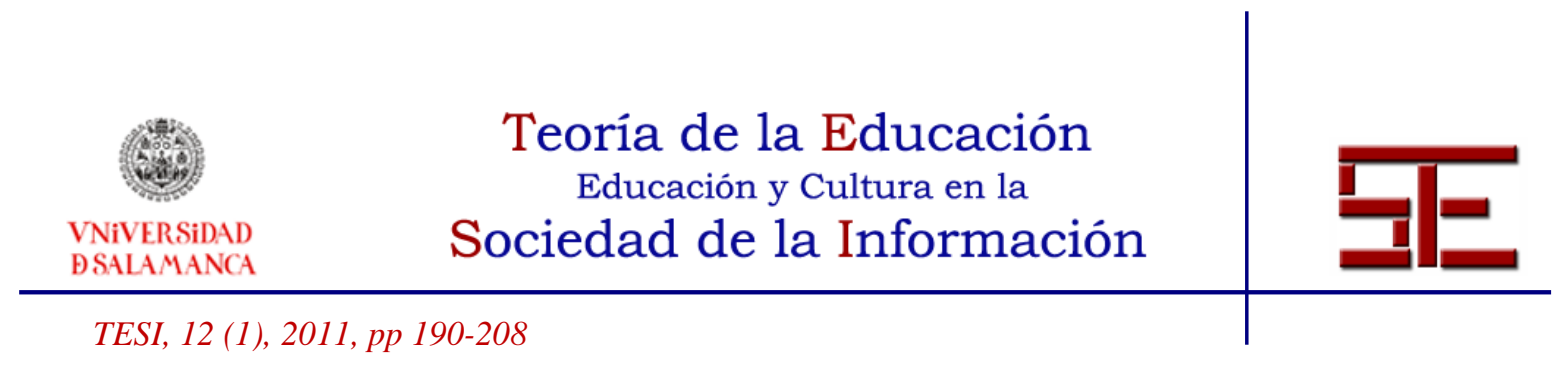

estudiantes que diseñaran un proyecto de intervención orientado al desarrollo y a la promoción socio-cultural y educativa de un ámbito rural desfavorecido. Para ello, debían emplear diferentes fuentes de información digital. Destacamos de entre las enunciadas por Brocos (2009), las siguientes:

1. Fuentes de información institucionales, a través de la visita del sitio web oficial de los Ayuntamientos de las localidades rurales seleccionadas por los estudiantes para implementar su proyecto y obtener información sobre el contexto real.

2. Fuentes de información geográfica y estadística, encaminadas a obtener información concreta de cada localidad rural para facilitar la delimitación de las posibles carencias socio-formativas de la misma.

3. Fuentes de información normativas necesarias para consultar las convocatorias oficiales de subvenciones a través del BOE, BOPA, etc. y establecer un presupuesto realista necesario para poner en marcha el proyecto.

4. Fuentes de información bibliográficas, de diversa índole para fundamentar y justificar las propuestas de actuación que cada grupo de estudiantes proponen en función de las necesidades detectadas.

Así, a través de la planificación y realización del proyecto los estudiantes trabajan conceptos básicos de la economía, desarrollo sostenible del medio rural, respeto por el entorno, promoción del medio rural, organización y gestión de recursos humanos y materiales, etc. Y la simulación se propuso como una estrategia de aprendizaje eficaz y motivadora que ayudaba a explicar todo el proceso de ejecución del mismo.

Conceptualmente, se pretende situar al estudiante en un contexto que imite algún aspecto de la realidad, reproduciendo en ese ambiente situaciones similares a las que podrá desarrollar como profesional independiente. Con la simulación se busca acelerar el proceso de aprendizaje y contribuir a potenciar su calidad, pero no puede constituir un elemento aislado dentro del proceso docente, sino un factor integrador, que articule dicho proceso, de ahí que lo hayamos considerado como una práctica innovadora íntimamente ligada a la consecución de los objetivos de la propia asignatura, y orientada a la preparación de los estudiantes para su futura vida laboral en tanto agentes de intervención socio-educativa, potenciando la adquisición de competencias específicas del grado de pedagogía (Del Moral; Villalustre, 2008b).

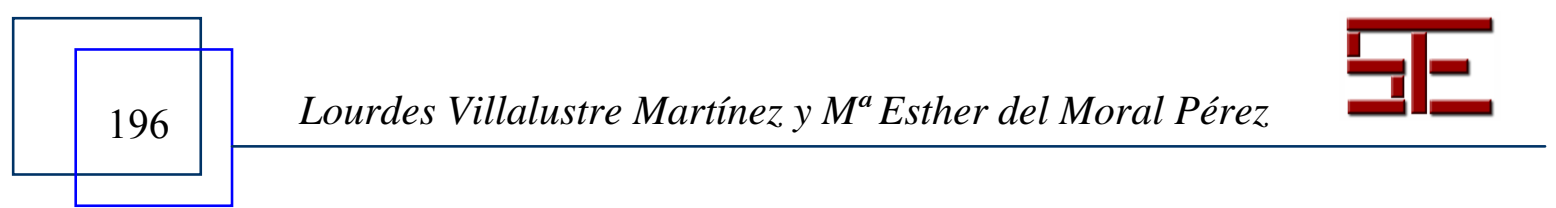



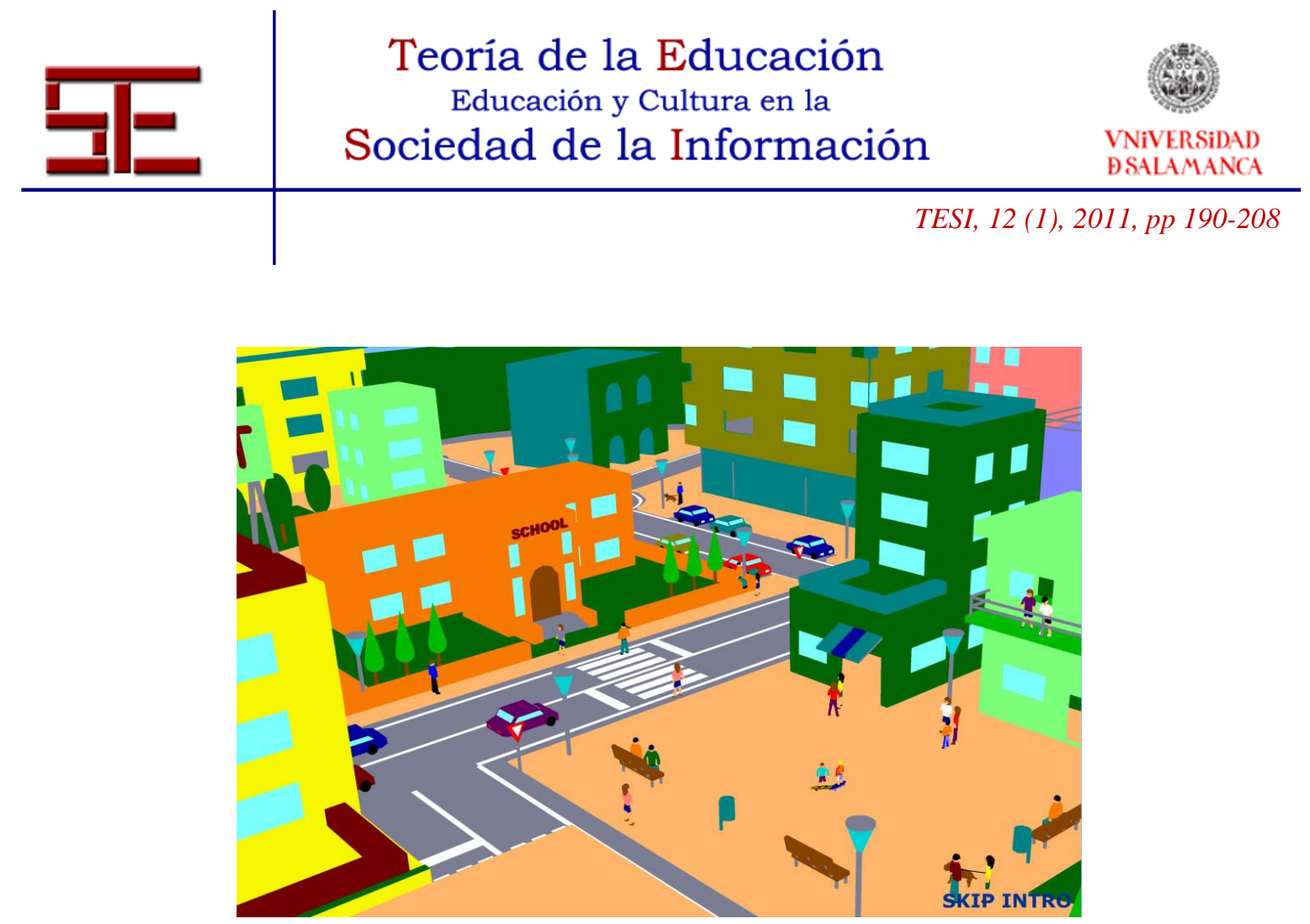

FIGURA 1. Secuencia del clip de película utilizada en la presentación del proyecto "Introducción" Gameproyect.

La realización del proyecto colaborativo propuesto, centrado en el desarrollo de una iniciativa empresarial que los estudiantes deben llevar a cabo, contribuye a:

- Facilitar su aprendizaje al permitirles poner en práctica los contenidos teóricos aprendidos de la asignatura.

- Concentrarse en el logro de determinados objetivos de la materia, así como en el desarrollo de las competencias específicas para simular la puesta en práctica de su propuesta.

- Reproducir una experiencia exitosa, contextualizándola y adaptándola a las demandas del entorno social y del colectivo al que se dirigen en cada caso.

- Planificar una actuación atendiendo al logro de los objetivos propuestos, ajustándose a los recursos humanos y económicos con los que se cuenta.

- Autoevaluarse de forma realista, tras conocer los criterios que servirán para valorar sus ejecuciones, tanto personales como colectivas.

- Minimizar la brecha entre la teoría académica y la práctica laboral.

La presentación del proyecto que debían realizar los estudiantes se hace a partir de un esquema de trabajo que se basa en la metodología de las Webquests, en donde se han concretado los diferentes elementos que la componen (introducción, tarea, procesorecursos, evaluación). Para acceder a los elementos de la Webquest es necesario

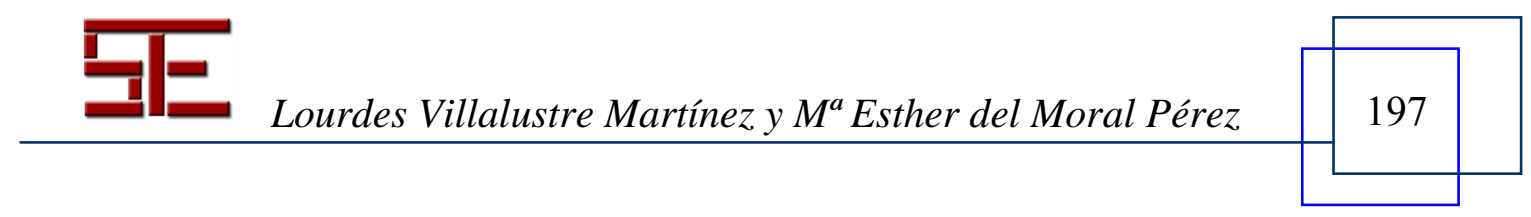




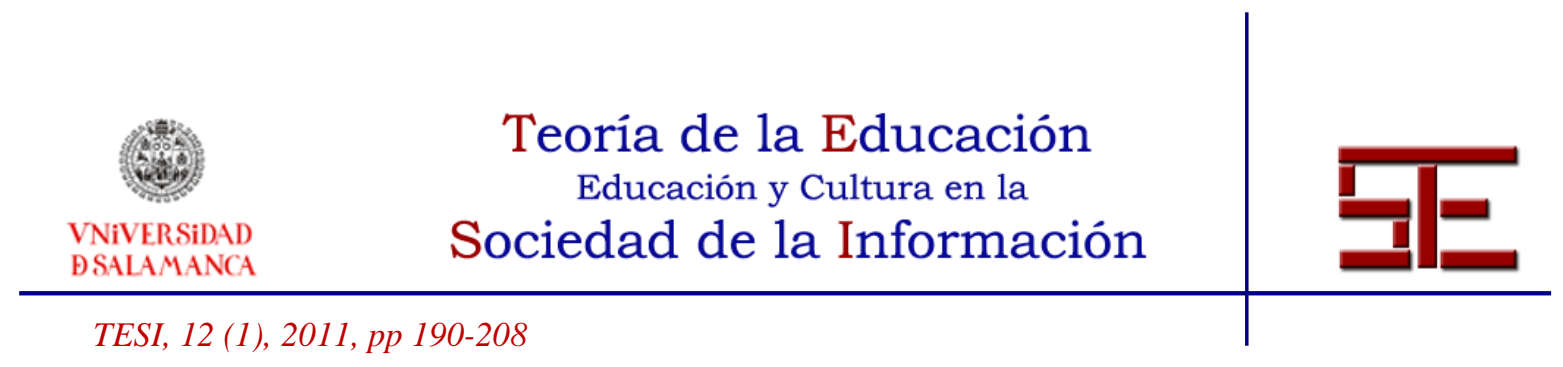

introducirse, de forma virtual, en una escuela -mediante la metáfora gráfica del plano de una casa-, en donde quedan visibles tres puertas, a través de cada una de ellas, se accede a un aula en la que se detallan diferentes aspectos básicos necesarios para llevar a buen término el proyecto que los estudiantes deben desarrollar.

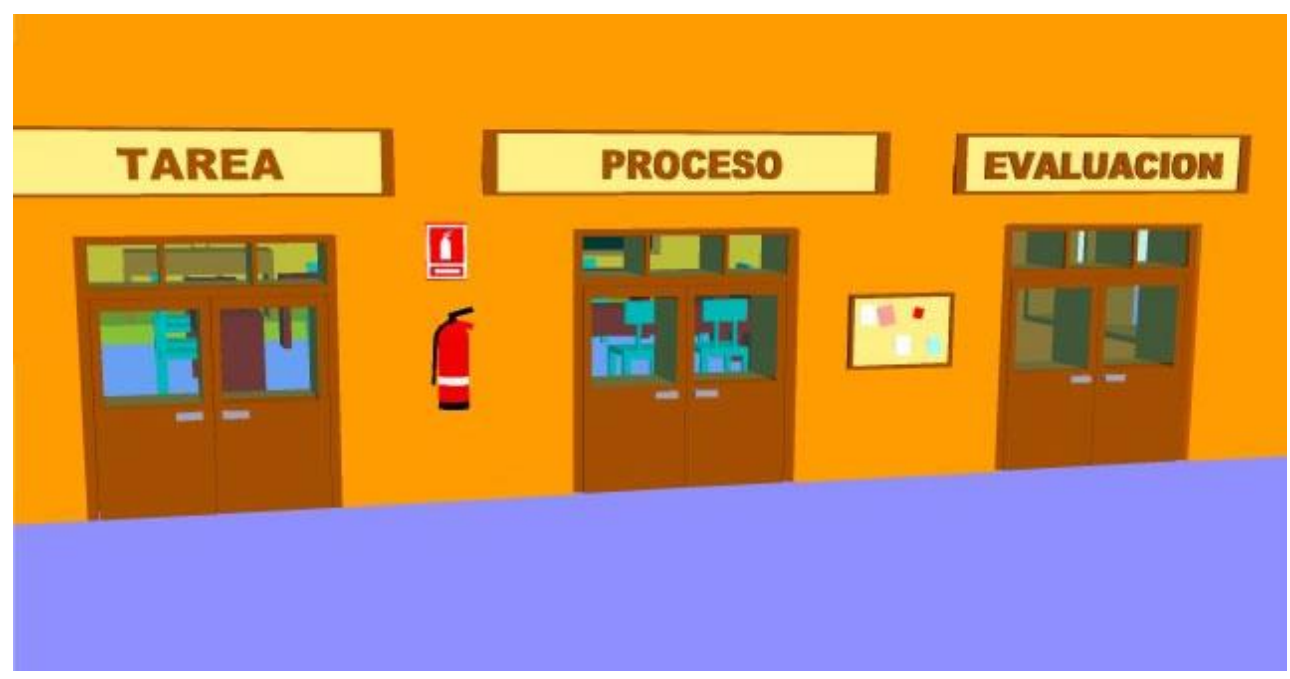

FIGURA 2. Elementos de la Webquest Gameproyect a través de los cuales se detallaba el objetivo del proyecto.

A continuación, se desvela lo que encontraban tras acceder a cada puerta:

- $I^{a}$ Puerta: se enuncia "la tarea"; en ella, se especifica el objetivo final del proyecto y las partes de las que debe constar. Para ello, se muestra un grupo de personas alrededor de una mesa con actitud de diálogo, los cuales se constituyen en botones interactivos, que si se presiona sobre ellos ofrecen información relevante sobre los apartados que debe tener el proyecto final.

- $2^{a}$ Puerta: "el proceso"; mediante el cual se muestran detalladamente los "pasos" que deben seguir para llevar a cabo el proyecto de manera colaborativa, empleando la metáfora de unos pies que avanzan al mismo tiempo que se progresa en la exposición del proceso. En este entorno se introducen enlaces a los contenidos o "recursos" formativos de la asignatura, direcciones web seleccionadas previamente por las docentes, etc., que los estudiantes pueden consultar para desarrollar el proyecto.

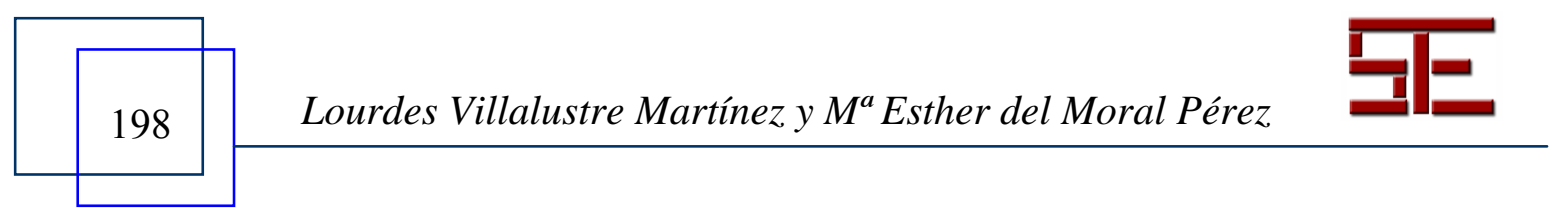




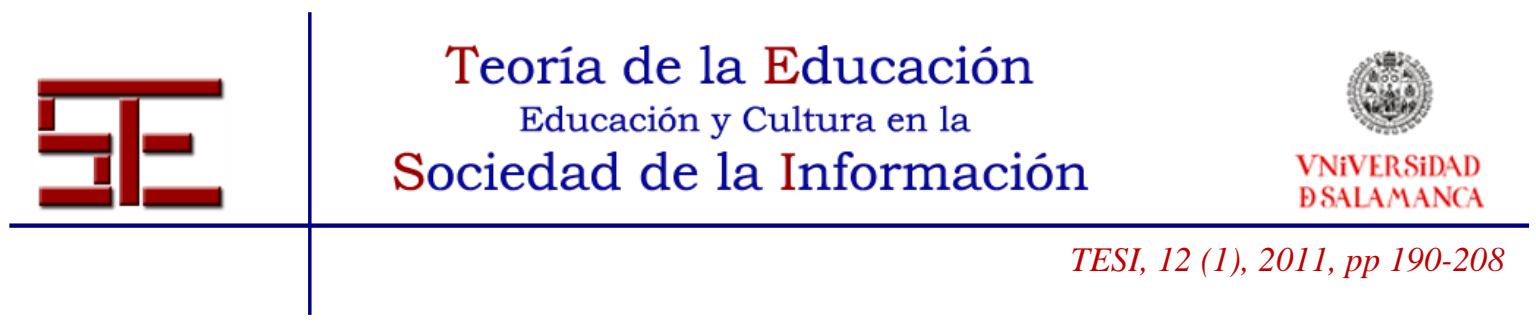

- $3^{a}$ Puerta: "la evaluación"; en esta sala se detalla, a través de una pequeña animación, los criterios de evaluación y los pesos asignados a cada una de las fases y elementos delimitados en el entorno "tarea", que configuran los componentes básicos del proyecto empresarial que deben realizar. También se muestran otros aspectos objeto de evaluación, tales como la calidad en la presentación del trabajo final, las aportaciones personales, etc.

Para la ejecución de este trabajo colaborativo, los diversos grupos de estudiantes disponían de diferentes herramientas tecnológicas que contribuyeron a la creación de espacios sociales que favorecieron el desarrollo de la actividad grupal diseñada para Ruralnet.

Como lo que se pretendía era facilitar el intercambio de información, el acceso a recursos compartidos, la posibilidad de participar en la redacción de una publicación conjunta entre diversos miembros de la comunidad de aprendizaje constituida, etc., se decidió activar dentro de la plataforma Moodle las wikis, las cuales permitieron ampliar las posibilidades de comunicación, interacción e intercambio de información entre los estudiantes de Ruralnet. Se crearon tantas wikis como grupos de trabajo se generaron en la asignatura, dando origen a pequeños cubículos de conocimiento, que con un carácter integrador permitían ensamblar las distintas aportaciones de los estudiantes, y de este modo pergeñar el proyecto de intervención de forma colaborativa.

Todas las wikis creadas para la realización del trabajo grupal tenían una misma estructura, la cual pretendía facilitar las dinámicas de interacción entre los miembros de cada micro-comunidad de aprendizaje generada en la materia. Dicha estructura viene dada por los apartados ya enunciados anteriormente en el Gameproyect, en donde se especifican detalladamente los cinco apartados de los que debe constar el proyecto.

En cada wiki se incorporaron varios enlaces hipertextuales (Figura 3) para que los estudiantes de cada grupo pudieran desarrollar su propio proyecto y generar conocimiento de manera colaborativa sobre aspectos relativos a la:

1. Descripción de la población rural seleccionada.

2. Delimitación de las necesidades de dicha población.

3. Enumeración de objetivos y actividades.

4. Especificación de fuentes de financiación.

5. Definición de la estructura organizativa que se adopte en cada iniciativa creada.

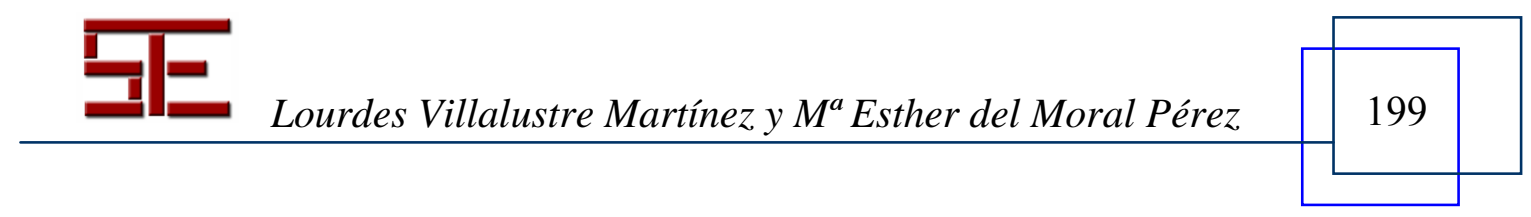



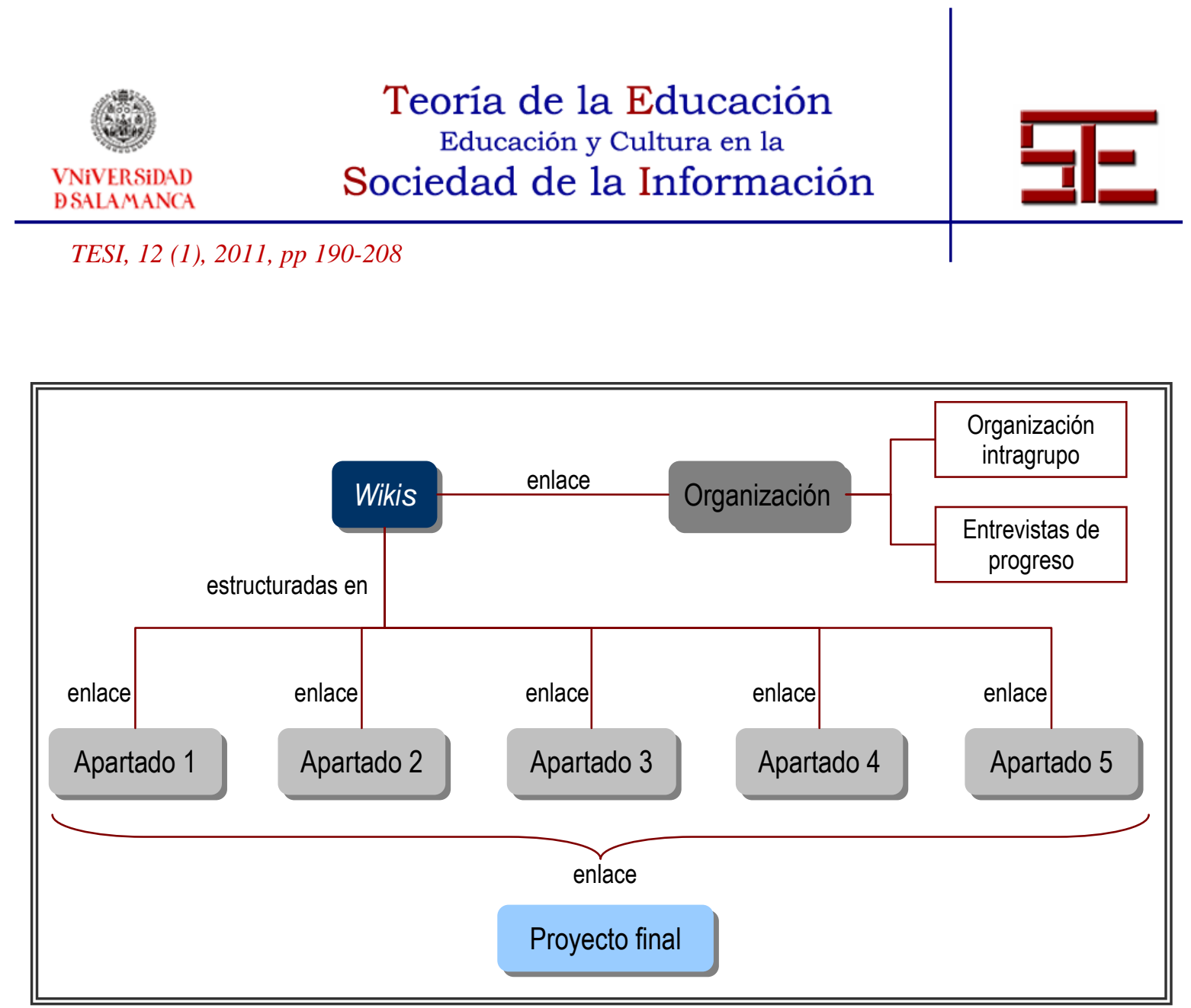

FIGURA 3. Estructura organizativa adoptada para facilitar el desarrollo del trabajo colaborativo de la asignatura a partir de Wikis (Del Moral; Villalustre, 2008c).

Asimismo, además de los cinco enlaces principales a nuevas páginas en las que los estudiantes podían ir incorporando toda la información necesaria para elaborar su actividad grupal, se generó una más (Figura 3) destinada a facilitar la organización intragrupo, en la que cada integrante del equipo podía incorporar mensajes de aviso, recordatorios, notas, etc., para sus compañeros. Igualmente, a través de este enlace se desarrollaron las entrevistas de seguimiento que las tutoras llevaron a cabo con los diferentes grupos de trabajo para orientar, asesorar y guiar a los estudiantes.

Tras desarrollar la actividad colaborativa, empleando las diferentes herramientas sociales presentes en la plataforma institucional de formación, entre ellas las wikis, se ha indagado sobre las competencias genéricas que los discentes manifiestaron haber desarrollado y/o consolidado con la actividad grupal propuesta en la asignatura, cuyos resultados se muestran en el siguiente apartado.

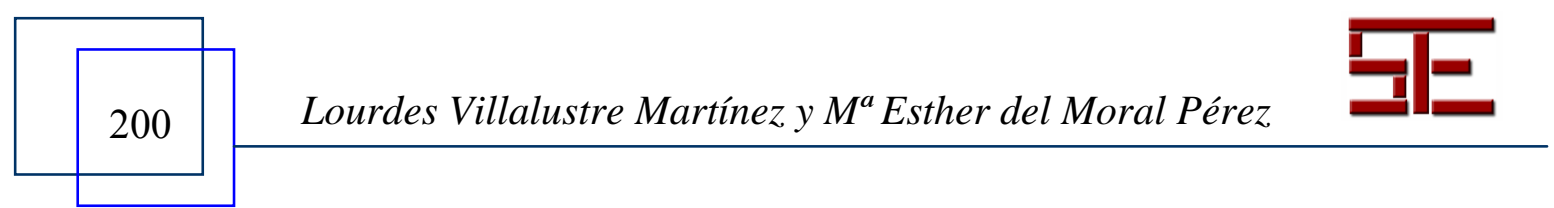




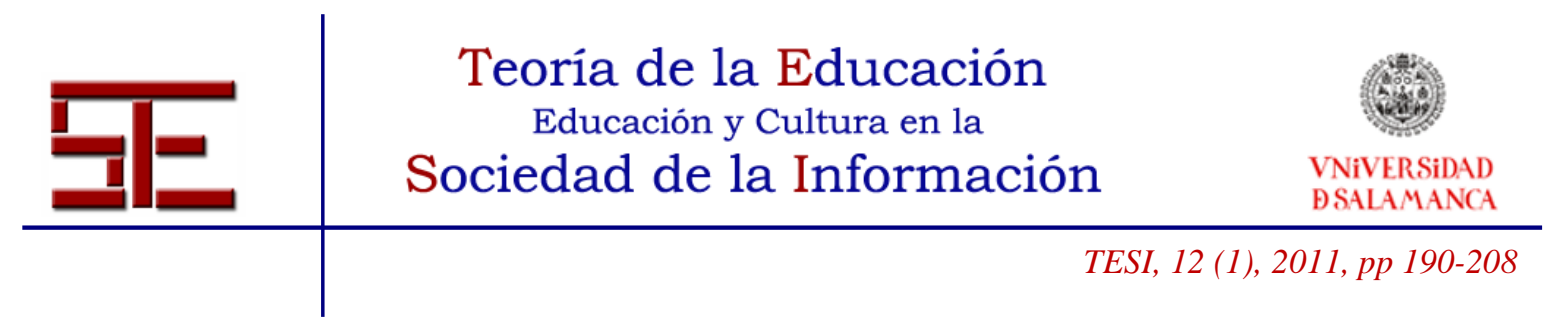

\section{3.- GAMEPROJECT Y COMPETENCIAS GENÉRICAS QUE LOS DISCENTES PERCIBIERON DESARROLLAR}

\subsection{Contexto}

En la asignatura virtual Ruralnet se ha adoptado un modelo de enseñanza abierto y flexible mediante la concreción de un diseño pedagógico basado en la realización de diferentes tareas que pretenden propiciar el desarrollo de numerosas competencias altamente demandadas por la sociedad actual. Entre ellas, la realización de un proyecto colaborativo presentado a través del Gameproject, el cual se basa en la filosofía de las Webquests, y articulado a través de una wiki.

Paralelamente al desarrollo de la actividad colaborativa a lo largo de varios cursos académicos, se recabó información sobre la percepción manifestada por los discentes en cuanto a las competencias de carácter genérico que consideraron haber desarrollado y/o consolidado con la misma.

\subsection{Muestra e instrumento de recogida de información}

La muestra estuvo constituida por 161 estudiantes, los cuales representaban el $83 \%$ de los discentes que concluyeron la asignatura.

El 52\% de los mismos procedía de la Universidad de Oviedo, como era previsible pues la mencionada asignatura es ofertada al CVC del G9 por dicha universidad; seguida por las universidades Pública de Navarra, Zaragoza, Extremadura y Cantabria con un $11,8 \%, 10 \%, 8,6 \%$ y 7,4\% respectivamente. El resto de universidades (País Vasco, Castilla La Mancha, La Rioja y Baleares) aglutinan a estudiantes con porcentajes que oscilan entre el 0,6\% y el 3,7\%. Siendo las titulaciones de Pedagogía y Magisterio (38\% y $22 \%$ respectivamente) las que reúnen a un mayor número de discentes. Aunque se notó el incremento progresivo de estudiantes procedentes de otras como Terapia Ocupacional (7\%), Medicina (5\%), Enfermería (3\%), Ingeniería Industrial (3\%), Trabajo Social (3\%), etc.

Para recabar la información se empleó un cuestionario elaborado ad hoc, el cual estaba integrado por los siguientes apartados:

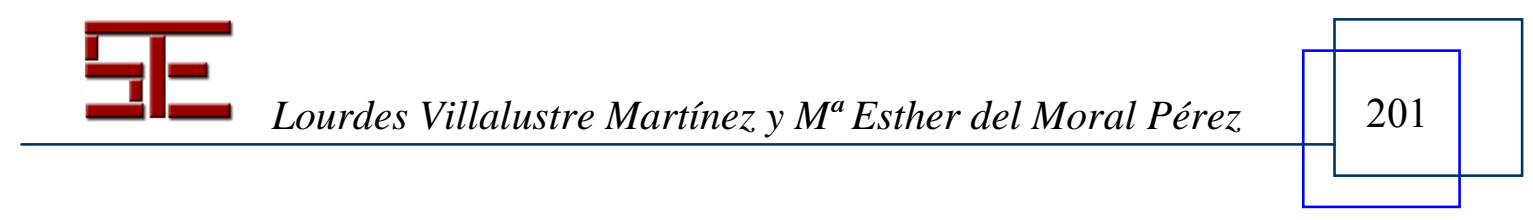




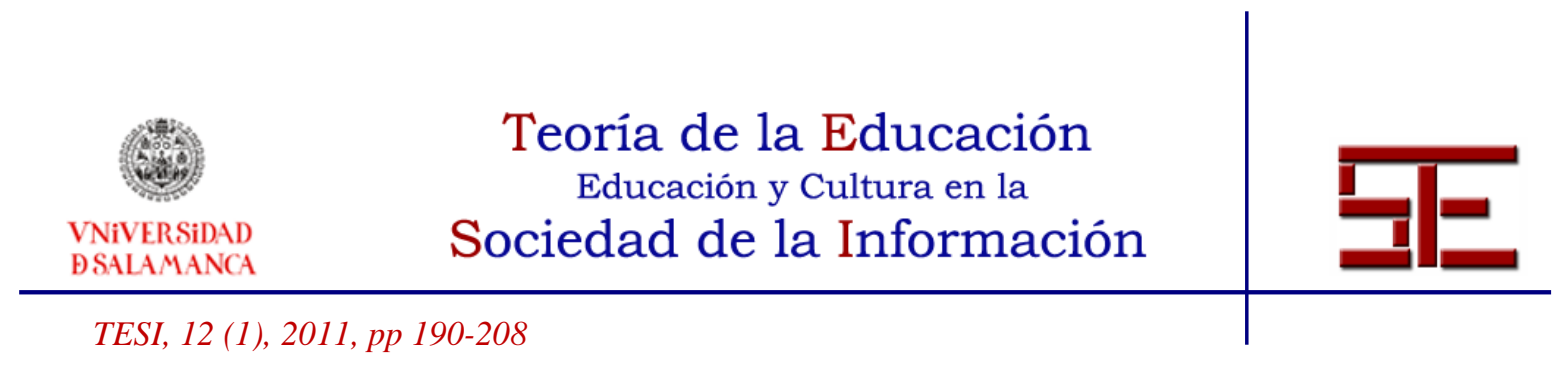

1. Datos de identificación de la muestra.

2. Datos específicos sobre el nivel de satisfacción de los estudiantes en relación a las e-actividades desarrolladas, identificando las valoraciones de los discentes sobre cada una de ellas, la utilidad percibida de cada cual, el nivel de dificultad detectado, etc. Descrito con detalle en Villalustre (2009).

3. Datos sobre las competencias genéricas que manifiestan los discentes haber desarrollado y/o consolidado con las prácticas formativas propuestas.

\subsection{Presentación de resultados}

Tras concluir el trabajo colaborativo propuesto, se recabó información sobre qué tipo de competencias genéricas (instrumentales, interpersonales y sistémicas) manifestaban los estudiantes, -a lo largo de los tres cursos académicos analizados-, haber desarrollado y/o consolidado a través de la realización de la mencionada actividad grupal. Cuyos datos se presentan en la siguiente tabla:

\begin{tabular}{|c|c|c|c|c|}
\hline Competencias genéricas & 1er Año & $2^{\circ}$ Año & 3er Año & $\begin{array}{c}\text { Muestra } \\
\text { total }\end{array}$ \\
\hline Capacidad de análisis & $70 \%$ & $58 \%$ & $50 \%$ & $61 \%$ \\
\hline $\begin{array}{l}\text { Conocimientos básicos de la } \\
\text { materia }\end{array}$ & $85 \%$ & $81 \%$ & $71 \%$ & $80 \%$ \\
\hline Comunicación escrita & $39 \%$ & $43 \%$ & $67 \%$ & $48 \%$ \\
\hline $\begin{array}{l}\text { Habilidades de gestión de la } \\
\text { información }\end{array}$ & $56 \%$ & $45 \%$ & $48 \%$ & $50 \%$ \\
\hline Organización y planificación & $48 \%$ & $74 \%$ & $76 \%$ & $64 \%$ \\
\hline $\begin{array}{l}\text { Manejo de herramientas } \\
\text { informáticas }\end{array}$ & $58 \%$ & $47 \%$ & $55 \%$ & $53 \%$ \\
\hline Trabajo en equipo & $62 \%$ & $74 \%$ & $74 \%$ & $69 \%$ \\
\hline $\begin{array}{l}\text { Aportar ideas innovadoras y } \\
\text { creativas }\end{array}$ & $55 \%$ & $66 \%$ & $62 \%$ & $60 \%$ \\
\hline $\begin{array}{l}\text { Desarrollo de habilidades para } \\
\text { liderazgo }\end{array}$ & $30 \%$ & $26 \%$ & $26 \%$ & $28 \%$ \\
\hline Diseño y gestión de proyectos & $61 \%$ & $60 \%$ & $57 \%$ & $60 \%$ \\
\hline Iniciativa y espíritu emprendedor & $41 \%$ & $53 \%$ & $45 \%$ & $46 \%$ \\
\hline
\end{tabular}

TABLA 1. Competencias de carácter genérico que los discentes manifestaron haber desarrollado y/o consolidado con el trabajo grupal propuesto.

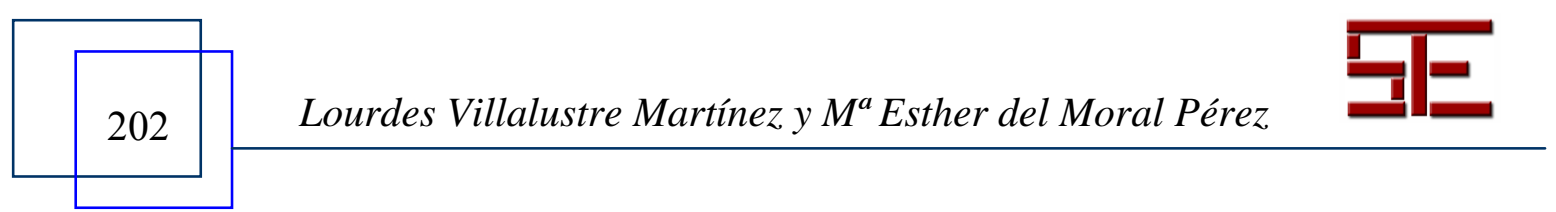




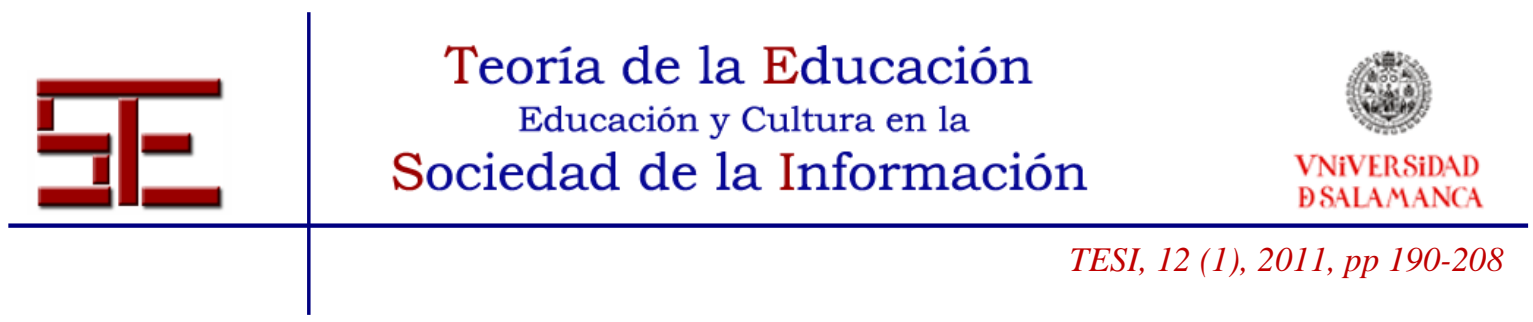

Un $80 \%$ de los estudiantes declararon que con la ejecución del trabajo grupal adquirieron conocimientos básicos de la materia, lógicamente, como era de esperar ya que éste estaba íntimamente ligado a los contenidos de la misma. Y los materiales didácticos elaborados específicamente para la asignatura se proponían como manuales de consulta para su realización, junto a otros recursos didácticos complementarios, tales como artículos de revistas y aportaciones de congresos y jornadas, legislación, enlaces web, etc.

Otras competencias que los discentes manifestaron haber desarrollado con el Gameproyect eran aquellas íntimamente relacionadas con la fase de organización y planificación (64\%) y gestión de la información (50\%), todas ellas inherentes a la ejecución de un proyecto, en este caso de carácter colaborativo. Al igual que la capacidad de análisis (61\%) necesaria para discriminar y valorar la información recabada a lo largo del trabajo grupal.

Entre las competencias instrumentales que, según los estudiantes, han desarrollado con el proyecto colaborativo han sido la comunicación escrita, con $48 \%$ y habilidades para el uso de herramientas informáticas (53\%) necesarias para desarrollar el trabajo colaborativo a través de las wikis habilitadas con este fin en la plataforma institucional de teleformación empleada.

En relación a las competencias interpersonales que los discentes manifiestan haber desarrollado con el proyecto, un alto porcentaje (69\%) establece que han puesto en práctica habilidades para el trabajo en equipo puesto que, como ya se ha mencionado, éste debía efectuarse necesariamente de forma colaborativa.

De modo similar, entre las competencias sistémicas que los discentes declaran haber desarrollado, en mayor medida, se encuentran las habilidades para diseñar y gestionar proyectos, y su capacidad para aportar ideas innovadoras y creativas, ambas con un $60 \%$. Evidentemente, necesarias para crear una iniciativa novedosa y con ciertas garantías de éxito que favorezca el desarrollo de una población rural desfavorecida, determinada previamente por ellos. En este sentido, un $46 \%$ de los mismos establece que con el diseño del proyecto han incrementado su espíritu emprendedor.

Por último, su consideración sobre si esta actividad ha contribuido al desarrollo de habilidades para el liderazgo queda restringida a un $28 \%$ de los estudiantes, puesto que

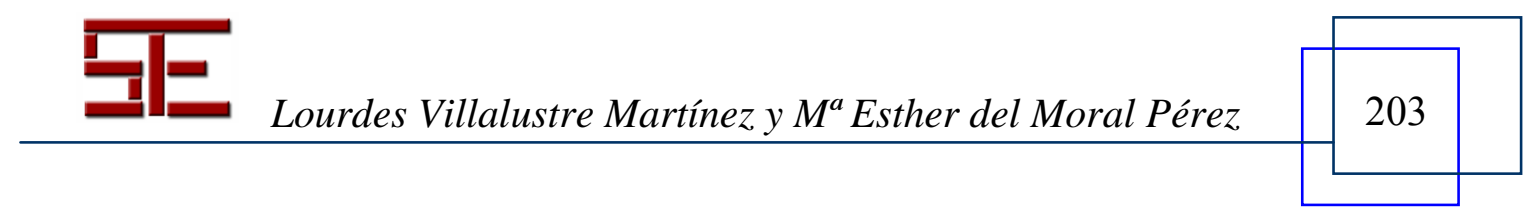




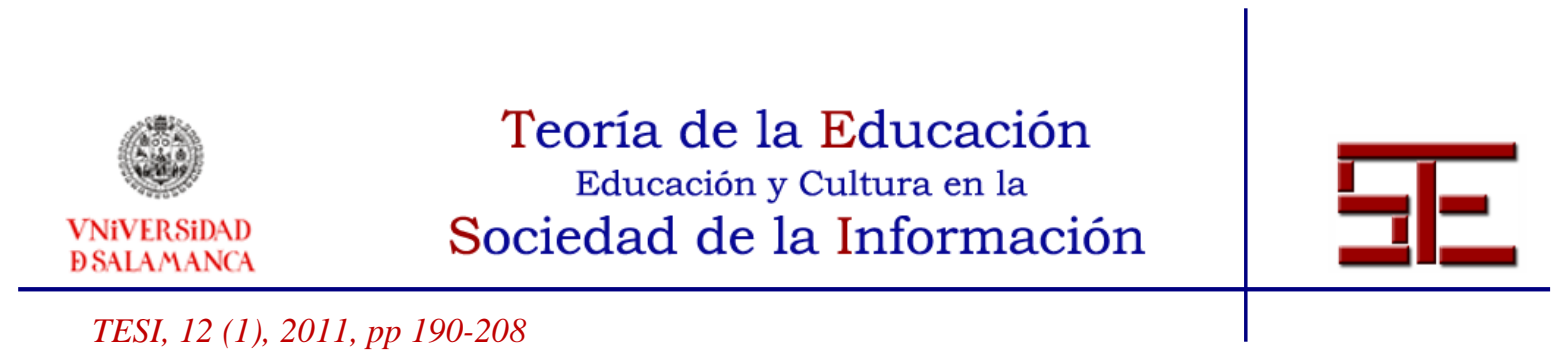

generalmente los grupos de trabajo eran liderados por una o dos personas, los cuales dinamizaban internamente los equipos, y no todos los estudiantes asumían ese papel.

Como se puede apreciar en la Tabla 1, apenas existen diferencias entre los cursos académicos analizados en cuanto a las competencias de carácter genérico que los discentes manifestaron haber adquirido y/o consolidado tras la realización del trabajo colaborativo propuesto, ya que éste fue el mismo en los tres cursos analizados, y por tanto, las competencias que se querían conseguir con él eran las mismas.

Un análisis estadístico minucioso, efectuado a través de la prueba Chi cuadrado, pudo determinar la existencia de diferencias significativas en función del curso académico analizado, poniendo de manifiesto que -a medida que se avanza en los años analizadoslos discentes manifiestan haber potenciado más su comunicación escrita $(\mathrm{P}=0,016), \mathrm{y}$ sus habilidades para recoger, organizar y gestionar la información $(\mathrm{P}=0,000 ; \mathrm{P}=$ 0,003). Ello puede explicarse, en gran medida, debido al especial hincapié, que desde la acción tutorial y la evaluación se hacía, para que los estudiantes utilizaran fuentes documentales actuales y con rigor académico, solicitándoles que elaborasen informes con calidad en su redacción, lo cual se reflejó en sus valoraciones.

De igual modo, se pudo apreciar que aquellos estudiantes que no contaban con experiencia previa en cursos de formación virtual consideraron haber desarrollado y/o consolidado en mayor medida la competencia genérica relacionada con el uso de herramientas informáticas $(\mathrm{P}=0,010)$. Dato que nos revela que los esfuerzos desarrollados desde la acción tutorial encaminados a favorecer y potenciar el uso de wikis para el desarrollo del trabajo grupal dieron su fruto, ya que aquellos estudiantes con menos experiencia previa en el manejo de este tipo de herramientas eran los más reticentes a la hora de utilizarlas.

\section{4.- CONCLUSIONES}

Adoptar una metodología basada en el trabajo colaborativo exige al docente una planificación y organización previa que puede verse facilitada por la aplicación de diversas estrategias didácticas, tales como las Webquests. Aunque un paso más allá lo representa Gameproyect -desarrollado en la asignatura Ruralnet-, que añade un componente lúdico a la exposición del proyecto, dotándola de un efecto motivador añadido, y que a través del apoyo de herramientas sociales como las wikis propician un aprendizaje más activo y constructivo.

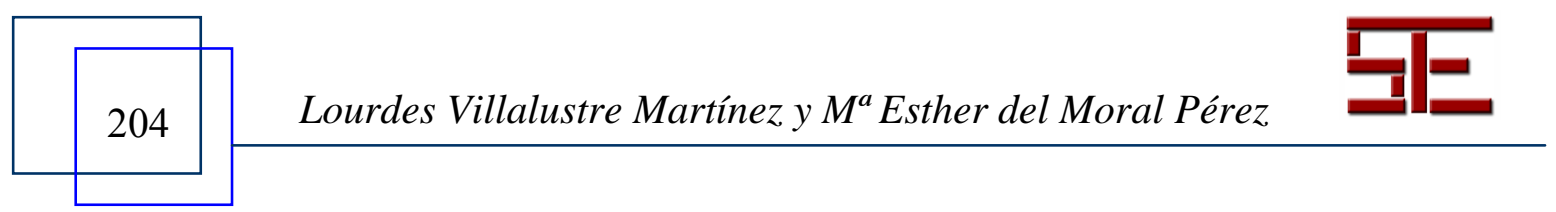




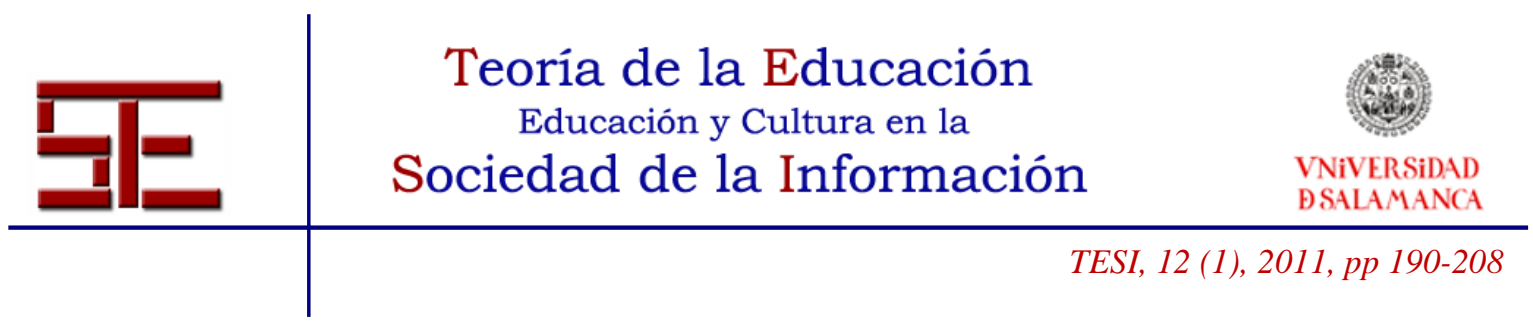

Desde la perspectiva docente, estaba claro que la propuesta de realización de un proyecto colaborativo -Gameproyect-, implicaba de forma activa a todos los agentes involucrados en el proceso de enseñanza-aprendizaje y propiciaba la adquisición de competencias específicas y genéricas que cualificaran a los estudiantes para su actividad profesional. Sin embargo, se quiso constatar cuál era la percepción de los propios estudiantes al respecto, y se les preguntó por las competencias que consideraron haber desarrollado y/o consolidado con la realización del proyecto.

Así, hay que destacar que las competencias genéricas basadas en la adquisición de conocimientos básicos de la materia y el desarrollo de habilidades para el trabajo en equipo han sido las competencias más desarrolladas con el trabajo grupal propuesto en la asignatura, tal y como lo han percibido los estudiantes universitarios que la cursaron.

Se encontraron diferencias significativas en cuanto a las competencias genéricas que los estudiantes consideraron haber desarrollado y/o adquirido con el trabajo grupal propuesto en función del año analizado, ya que a medida que se avanzaba en el estudio los discentes percibían desarrollar más su comunicación escrita y sus habilidades para recoger, organizar y gestionar la información. De igual modo, se ha podido apreciar que aquellos estudiantes que carecían de experiencia previa en cursos de formación virtual consideraban, lógicamente, haber desarrollado y/o consolidado en mayor medida la competencia genérica relacionada con el uso de herramientas informáticas.

Desde aquí, entendemos que la realización de proyectos de manera colaborativa puede ser una práctica formativa que permite a la comunidad de estudiantes, que integran un determinado grupo de trabajo, desarrollar habilidades y competencias que den lugar a un aprendizaje activo, constructivo y real (Jonassen, 2000), partiendo de las intervenciones individuales vertidas por cada miembro a la misma.

En definitiva, aplicar una metodología basada en la realización de proyectos colaborativos contribuye al desarrollo cognitivo de toda la comunidad, a partir del enriquecimiento suscitado a través de las opiniones e ideas individuales que cada miembro aporta a la misma, con el apoyo de las herramientas de comunicación on line, $\mathrm{y}$ de las interacciones que se producen entre docentes y estudiantes (Del Moral; Villalustre, 2006). Al mismo tiempo, posibilita una enseñanza flexible y abierta que potencia el trabajo autónomo de los estudiantes al proporcionarles un mayor control sobre su propio proceso de aprendizaje.

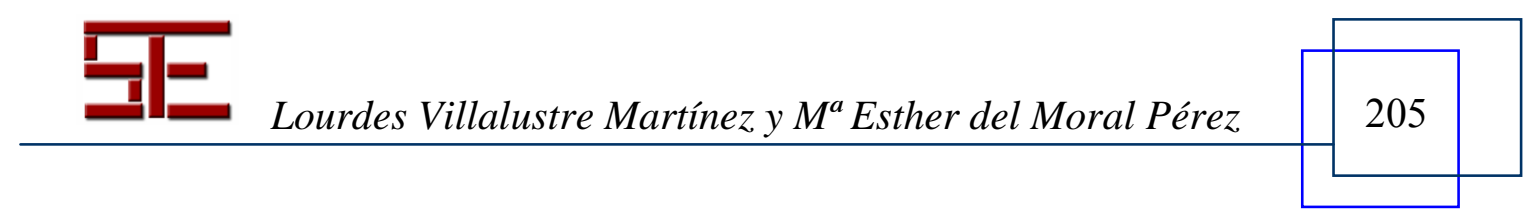




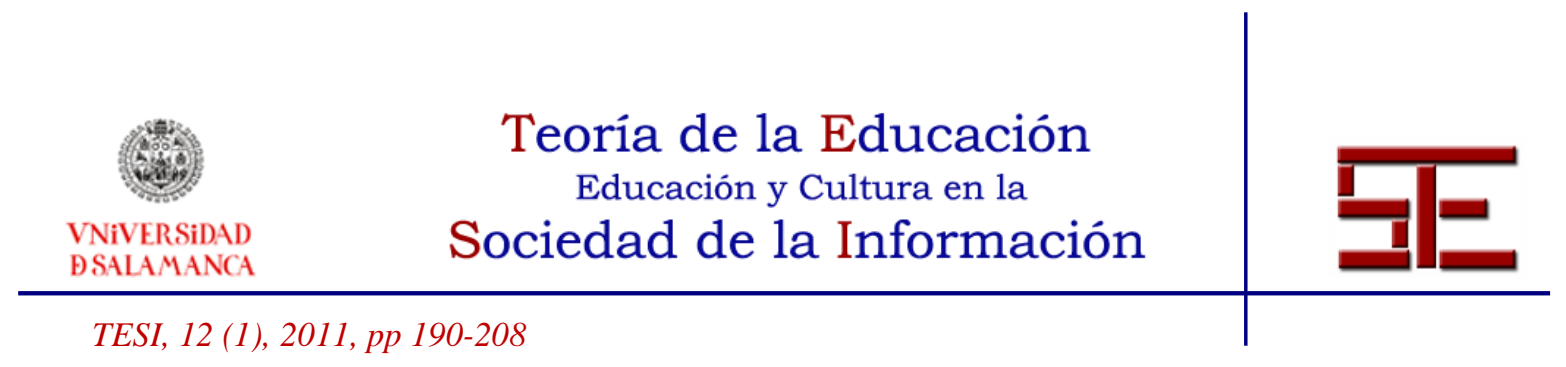

\section{5.- REFERENCIAS}

Barkley, E.; Cross, K. y Major, C. (2007). Técnicas de aprendizaje colaborativo. Ministerio de Educación y Ciencia. Madrid: Morata.

Brocos, J. M. (2009). Fuentes de información y bases de datos para la investigación en ciencia y tecnología. Estudio, análisis y búsqueda. Revista Electrónica Teoría de la Educación: Educación y Cultura en la Sociedad de la Información (TESI),10 (2), 167-191.

Del Moral, M.E. y Villalustre, L. (2005). Webquest: Una metodología para la investigación y el desarrollo de competencias en el EEES. Revista Comunicación y Pedagogía, 206, 27-33.

- (2006). Gameproyect: Una estrategia metodológica que favorece el trabajo colaborativo basado en las Webquests. Aula abierta, 87, 123-146.

- (2007a). Ruralnet: prácticas virtuales de aprendizaje colaborativo a través de Webquest. Revista de Medios y Educación: Píxel-Bit, 29, 25-35.

- (2007b). GameProject: A Multimedia Presentation Of A Joint Project For A Degree In Education. En e-Learn 2007. World Conference on E-learning in Corporate, Government, Healthcare and Higher Education. Québec City. Canada.

- (2008a). Las wikis vertebradoras del trabajo colaborativo universitario a través de WebQuest. Revista Latinoamericana de Tecnología Educativa (RELATEC), 7 (1), 73-83.

- (2008b). Sviluppo di progetti collaborativi in corsi universitari a partire da un gioco di simulazione e da Wiki. Revista Tecnologie Didattiche, 45(3), 31-37.

- (2008c). Desarrollo de competencias y estilos de aprendizaje en contextos virtuales: prácticas colaborativas y trabajo autónomo en Ruralnet. En Del Moral, M.E. y Rodríguez, R. (Comp.). Docencia Universitaria. Experiencias docentes y TIC. (pp. 97-129). Barcelona: Editorial Octaedro.

Dodge, B. (1995). Some Thoughts About WebQuest. Extraído en enero, 2011, de

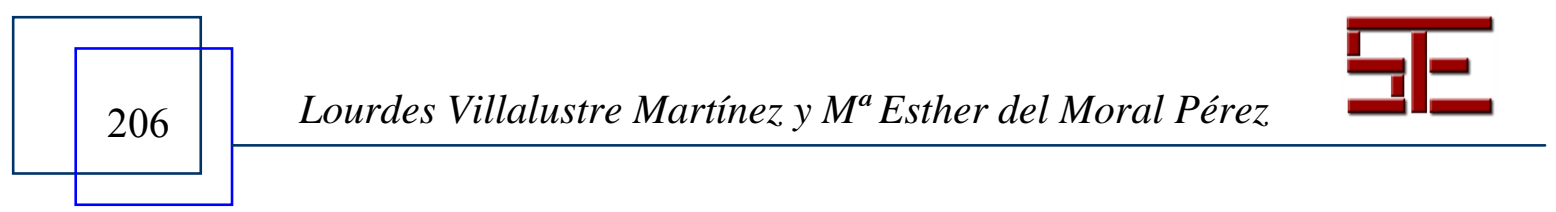




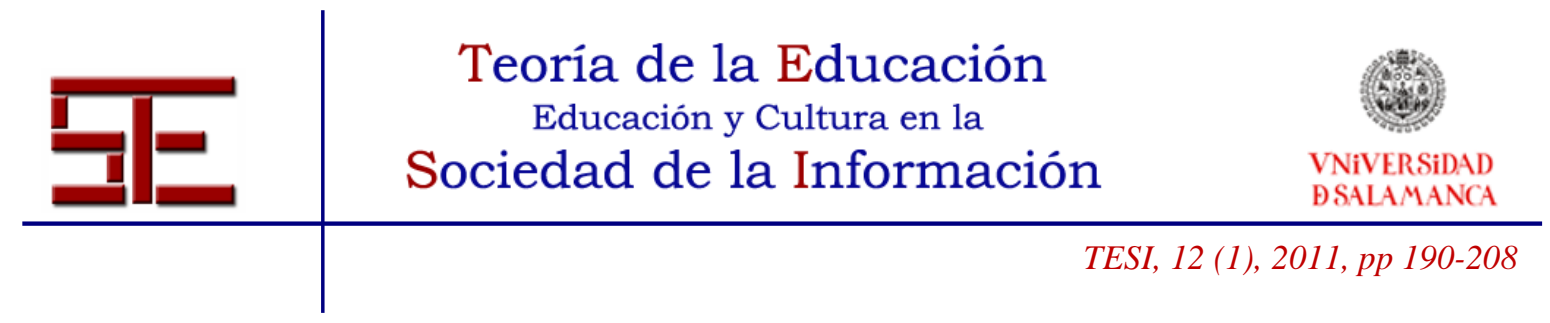

http://webquest.sdsu.edu/about_webquests.html.

- (1997). Building Blocks of a Webquest. Extraído en enero, 2011, de http://projects.edtech.sandi.net/staffdev/buildingblocks/p-index.htm

González, J. y Wagenaar, R. (Comps.) (2003). TUNING. Educational Structures in Europe. Informe Final del Proyecto Piloto - Fase 1. Bilbao: Universidad de Deusto.

Jonassen, D. (1999). Designing Constructivist Learning Environments. In Reigeluth, Ch. (Ed). Instructional-Design Theories and Models. A New Paradigm of Instructional Theory (pp. 215-240). New Jersey: Lawrence Erlbaum Associates.

- (2000). El diseño de entornos constructivistas de aprendizaje. En Reigeluth, C. (Ed.), Diseño de la instrucción. Teorías y modelos. Un nuevo paradigma de la teoría de la instrucción (pp. 225-249). Madrid: Editorial Santilla.

Lave, J. (1997). The culture of acquisition and the practice of understanding. En Kirshner, D. y Whitson, J. A. (Eds.), Situated cognition. Social, semiotic and psychological perspectives. (pp.17-35). Mahwah, NJ: Lawrence Erlbaum.

Owen, M., Grant, L., Sayers, S. \& Facer, K. (2006). Social software and learning. Extraído en diciembre, 2010, de http://www.futurelab.org.uk/research/opening_education.htm.

Scardamalia, M., Bereiter, C. \& Lamon, M. (1994). The CSILE project: Trying to bring the classroom into World 3. In K. McGilley (Ed.), Classroom lessons: Integrating cognitive theory and classroom practice (pp. 201-228). Cambridge, MA: MIT Press.

Villalustre, L. (2009). Innovaciones en Ruralnet: satisfacción de los estudiantes y competencias genéricas que perciben desarrollar en contextos virtuales. Tesis doctoral inédita. Universidad de Oviedo.

Vygotski, L. S. (1995). Historia del desarrollo de las funciones psíquicas superiores. En Vygotski, L. S. (Ed.). Obras escogidas III (vol. III) (pp.11-340). Madrid: Aprendizaje Visor.

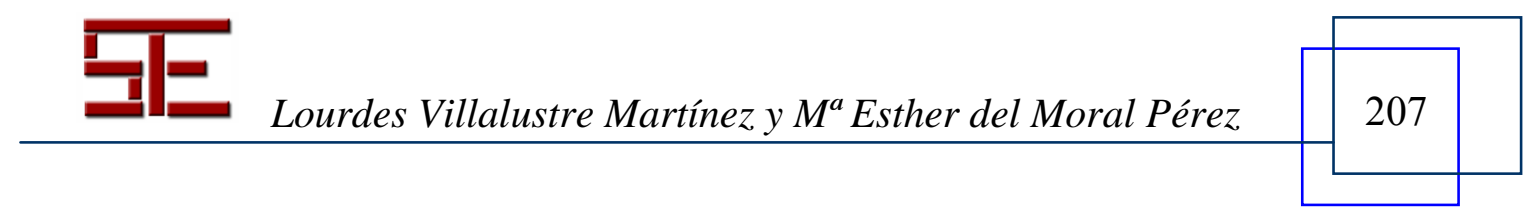


Wenger, E. (2001). Comunidades de práctica. Aprendizaje, significado e identidad. Barcelona: Paidós.

Para citar el presente artículo puede utilizar la siguiente referencia:

Villalustre Martínez, L. y Del Moral Pérez, M. E. (2011). Webquest y wikis: búsqueda de información en red y desarrollo de competencias en colaboración, en Hernández Serrano M. J. y Fuentes Agustí (Coords.) La red como recurso de información en educación. Revista Teoría de la Educación: Educación y Cultura en la Sociedad de la Información. Vol. 12, no 1. Universidad de Salamanca, pp. 190-208 [Fecha de consulta: $\mathrm{dd} / \mathrm{mm} / \mathrm{aaaa}]$.

http://campus.usal.es/ revistas_trabajo/index.php/revistatesi/article/view/7829/7856

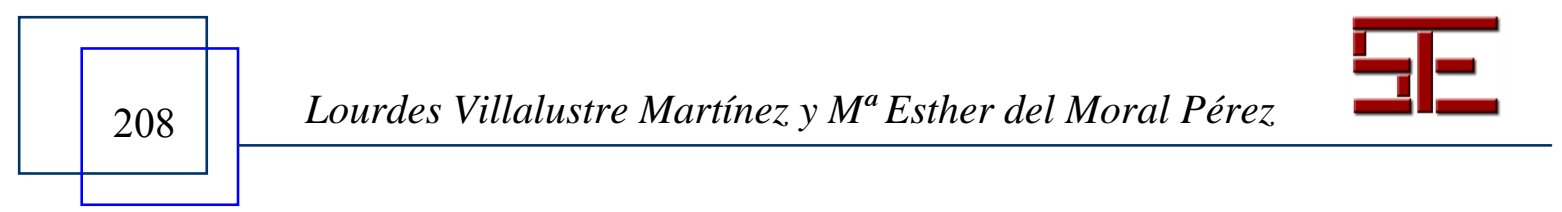

